\title{
A Retrospective Study on the Factors Affecting the Early Marginal Bone Loss of Tissue-Level Implants
}

\author{
Seong-Mo Koo, DDS, MSD', Dae-Young Kang, DDS, MSD, PhD², Pham-Duong Hieu, DDS, \\ MSD, PhD ${ }^{3}$, Hyun-Seung Shin, DDS, MSD, PhD ${ }^{4}$, Jung-Chul Park, DDS, MSD, PhD ${ }^{5 *}$ \\ ${ }^{1}$ Resident, Department of Periodontology, Dankook University Dental Hospital, College of Dentistry, Dankook \\ University, Cheonan, Korea \\ ${ }^{2}$ Clinical Assistant Professor, Department of Periodontology, Dankook University Dental Hospital, College of \\ Dentistry, Dankook University, Cheonan, Korea \\ ${ }^{3}$ Associate Dean, Department of Maxillo-Stomatology, Vietnam National University School of Medicine and \\ Pharmacy, Hanoi, Vietnam \\ ${ }^{4}$ Associate Professor, Department of Periodontology, Dankook University Dental Hospital, College of Dentistry, \\ Dankook University, Cheonan, Korea \\ ${ }^{5}$ Adjunct Professor, Department of Periodontology, Dankook University Dental Hospital, College of Dentistry, \\ Dankook University, Cheonan, Korea
}

*Corresponding author: Jung-Chul Park, Department of Periodontology, Dankook University Dental Hospital, 119 Dandae-ro, Dongnam-gu, Cheonan 31116, Korea

Tel : +82-41-550-0263. eFax : +82-303-3442-7364. E-mail : yonseimagic@gmail.com

\section{OPEN ACCESS}

pISSN 2765-7833

eISSN 2765-7841

Journal of implantology and applied sciences 2021; 25(4): 158-169

https://doi.org/10.32542/implantology.2021017

Received: November 12, 2021

Revised: December 13, 2021

Accepted: December 13, 2021

\section{Seong-Mo Koo}

http://orcid.org/0000-0001-7596-2667

Dae-Young Kang

http://orcid.org/0000-0002-4311-4118

Pham-Duong Hieu

http://orcid.org/0000-0001-5409-0361

Hyun-Seung Shin

http://orcid.org/0000-0002-1410-9731

Jung-Chul Park

http://orcid.org/0000-0002-2041-8047

Copyright $\odot$ 2021. The Korean Academy of Oral \& Maxillofacial Implantology

This is an Open Access article distributed under the terms of the Creative Commons Attribution Non-Commercial License (http://creativecommons. org/licenses/by-nc/4.0/) which permits unrestricted non-commercial use, distribution, and reproduction in any medium, provided the original work is properly cited.

\section{Abstract}

Purpose: Marginal bone loss (MBL) around dental implants adversely affects long-term implant treatment outcomes. The purpose of this study was to investigate the risk factors of MBL in tissuelevel implants.

Materials and Methods: The study included 42 patients with 69 tissue-level implants placed between May 2015 and January 2020 at the Department of Periodontology of Dankook University Dental Hospital. Patient and implant data were collected from medical records and panoramic and periapical radiographs. MBL was measured as the distance from the apex of the implant fixture to the most coronal point where the implant and bone meet, and calibration was performed using the actual length of the implant. Student's $t$-test was used to compare the groups by age ( $<60$ or $\geq 60$ years), sex (male or female), hypertension status, diabetes status, implant diameter $(<5.0$ or $5.0 \mathrm{~mm})$, implant length ( 7.0 or $\geq 8.5 \mathrm{~mm}$ ), position of implants (maxilla or mandible), collar height ( $\leq 2.0$ or $2.8 \mathrm{~mm}$ ), splinted implant prosthesis, and bone grafting on MBL. One-way ANOVA was used to compare the MBL of the three groups by implant insertion depth less than $0.5 \mathrm{~mm}$, between 0.5 to $1.0 \mathrm{~mm}$, and more than $1.0 \mathrm{~mm}$. The chi-square test for linear trend was used to determine whether the implant insertion depth affected the thread exposure.

Results: There was no statistically significant difference between the groups in terms of sex, age, hypertension, diabetes, diameter, length, location, collar height, splinted implant prosthesis, and bone grafting. One-way ANOVA showed that the MBL was significantly higher in the group with implant insertion depth $\geq 1.0 \mathrm{~mm}$ than in the other groups. However, the frequency of thread exposure decreased as the implant insertion depth increased. 
Conclusion: There were no statistically significant factors associated with MBL, except for implant insertion depth. As the implant insertion depth increased, the amount of MBL increased, but the frequency of thread exposure decreased.

Keywords: Bone resorption, Dental implants, Retrospective studies

\section{I . Introduction}

The use of dental implants to restore edentulous areas is well established and provides a high survival rate. ${ }^{1}$ However, a long-term observational study showed marginal bone loss (MBL) around implants, ${ }^{2}$ with most bone resorption around the implant initially occurring in marginal bone because of the concentration of occlusal loading around this area. ${ }^{3}$ With the progression of MBL, implants become susceptible to occlusal loading and plaque deposition. Therefore, preventing the resorption of marginal bone around the implant is crucial for the success and survival of implants. ${ }^{4}$

MBL can be influenced by various factors such as excessive occlusal force, trauma during surgery, previous periodontal lesions, peri-implantitis, and, especially, the micro-gap between fixture and abutment. ${ }^{5,6}$ The micro-gap has a range of $30-135 \mu \mathrm{m}^{7}$ and can cause inflammatory infiltration and bone resorption because of bacterial accumulation. ${ }^{8}$ Movement in the micro-gap can also cause bone resorption regardless of micro-gap size. ${ }^{9}$ In terms of micro-gap, tissue-level implants are advantageous for preventing MBL. Considering that implant-abutment interfaces exist in soft tissue rather than alveolar crestal bone in tissue-level implants, the micro-gap between the implant and abutment has little effect on bone tissue. ${ }^{10}$ Furthermore, the repetitive dis/reconnection of abutment during prosthetic procedures can destroy soft tissue sealing and cause bone resorption. ${ }^{11}$ For tissue-level implants, the implant-abutment interface is located at the tissue level where the dis/reconnection of the abutment inflicts less damage to surrounding soft tissues. ${ }^{12}$ Given these characteristics, it has been reported that MBL occurs little and that the bone level is maintained stably in tissue-level implants. ${ }^{13}$

However, because the smooth surface of tissue-level implants is unfavorable for osseointegration, MBL may increase if the implant is placed in the subcrestal position. ${ }^{14}$ Kumar et al. ${ }^{15}$ reported that when implants were placed in a subcrestal position, the MBL became significantly greater in tissue-level implants than in bone-level implants 12 months after implant placement.

The aim of this study was to investigate the factors affecting the initial MBL of tissue-level implants and whether there is a statistical significance between implant insertion depth and initial MBL. 


\section{Materials and Methods}

\section{Patient selection and implant characteristics}

This study had a single-center, retrospective, observational design. Patients who received implant treatment with tissue-level implants between May 2015 and January 2020 at Dankook University Dental Hospital and visited for regular check-up one year after implant placement were included in this study. A total of 42 patients and 69 implants were included in the study. All implants were tissue-level Stella ${ }^{\circledR}$ implants (Shinhung, Seoul, Korea), which have a sandblasted, large grit, acid-etched rough surface and a smooth surface collar. The collar height was 1.8 or $2.8 \mathrm{~mm}$ when the diameter of the implant was less than, $5.0 \mathrm{~mm}$ and was $2.0 \mathrm{~mm}$ when the diameter of the implant was $5.0 \mathrm{~mm}$ or more (Fig. 1).

\section{Treatment procedure}

All implant surgeries were performed at Dankook University Dental Hospital. Surgical procedures were conducted under local anesthesia induced by $2 \%$ lidocaine with 1:80,000 epinephrine (Huons, Seoul, Korea). After raising the full-thickness mucoperiosteal flap, tissue-level implants were placed. Bone grafting was performed in 22 cases with defects, such as dehiscence or fenestration around the implant. If implant stability and soft tissue healing status were appropriate at three to four months of follow-up, the patient was referred to the Department of Prosthodontics. Panoramic radiographs were obtained after implant surgery and approximately one year after implant placement.

\section{Demographic and implant-related data collection from medical records}

The demographic information and characteristics of each patient were collected from medical records. The factors analyzed in this study were 1) sex, 2) age, 3) hypertension, 4) diabetes mellitus, 5) implant diameter, 6) implant length, 7) implant collar height, 8) bone grafting, and 9) prosthesis splinting.

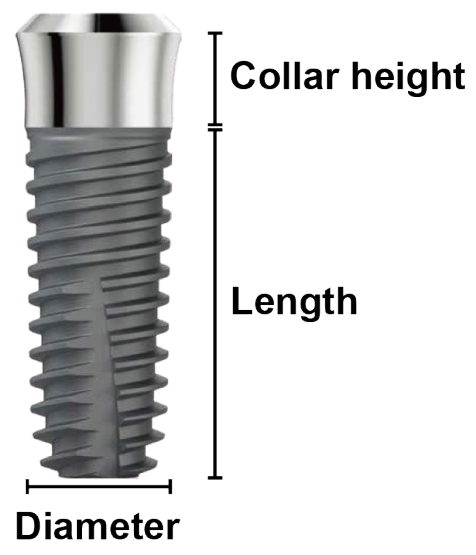

Fig. 1. Tissue-level implant (Stella ${ }^{\circledR}$, Shinhung, Seoul, Korea) used in this study. 


\section{Measurement of MBL with radiographs}

MBL was measured by comparing the panoramic radiographs or periapical radiographs taken immediately after implant surgery and one year after implant surgery. After acquiring the image file, the images were magnified by 300\% by using Adobe Photoshop 2020 (Adobe Systems, San Jose, CA, USA). Distances from the apex of the implant fixture to the first bone-to-implant contact on both the mesial and distal sides were measured. The implant insertion depth was set by subtracting the length of the implant from this distance. Actual MBL and implant insertion depth were calculated by calibrating the implant length (Fig. 2). Implant thread exposure was determined using the panoramic graph taken one year after surgery. If an implant thread was present above the uppermost part of the alveolar crest, it was thought that implant thread exposure had occurred.

\section{Statistical analysis}

All statistical analyses were performed using SPSS version 25 (SPSS, Chicago, IL, USA). The significance level was set at 0.05 . The Shapiro-Wilk test was used to test the normality of the distribution. The effects of sex, age, hypertension, diabetes, implant length, implant diameter, prosthesis splinting, and bone grafting on MBL were analyzed using Student's $t$-test. After dividing implants into three groups according to implant insertion depth shallower than $0.5 \mathrm{~mm}$ (group A), between 0.5 to $1.0 \mathrm{~mm}$ (group B), and deeper than $1.0 \mathrm{~mm}$ (group C), one-way ANOVA was used to analyze the effect of implant insertion depth on MBL. The chi-square test for linear trend was used to analyze the correlation between implant insertion depth and implant thread exposure. Dennett's T3 test was performed as a post hoc test.
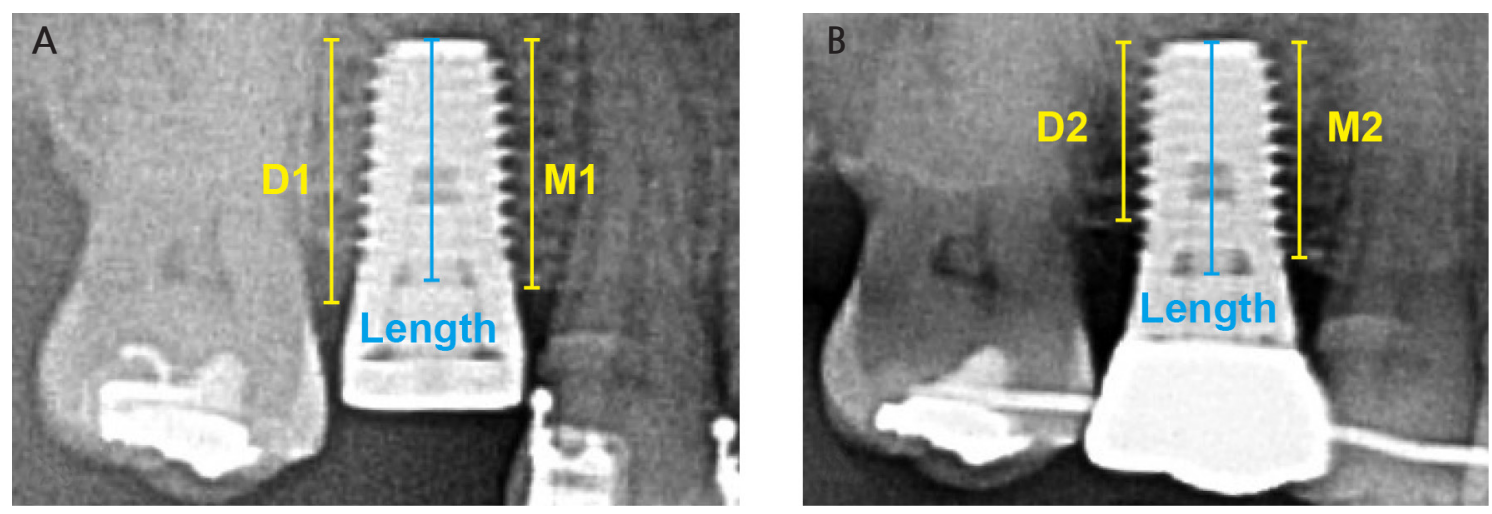

Fig. 2. Measurement of MBL and implant insertion depth. (A) Radiograph at the day of surgery, (B) Radiograph taken one year after implant surgery. The mesial MBL was obtained by subtracting M1 from M2, and the distal MBL was determined by subtracting D1 from D2. The implant insertion depth was obtained by subtracting the implant length from M1 and D1. Calibration was performed using implant length. 


\section{III . Results}

\section{Demographics and clinical outcomes}

The subjects consisted of 42 patients with 69 tissue-level implants. Among the 42 patients and 69 implants, 3 implants failed before functional loading. MBL was measured in 40 and 66 implants. The mean observation period was $12.8 \pm 3.9$ months. The difference in MBL between the mesial and distal sides was not statistically significant. The mean MBL, which was set as the average value of the mesial and distal MBL, was $0.38 \mathrm{~mm}$. Table 1 shows the distribution of implants. Sex, age, hypertension, diabetes, implant location, implant diameter, implant length, collar height, splinted prosthesis, and bone grafting were not significantly associated with MBL (Table 2).

\section{Table 1. Studies summarizing associated with implant deviation about implant location}

\begin{tabular}{|c|c|c|}
\hline \multicolumn{2}{|l|}{ Factors } & \multirow{2}{*}{$\begin{array}{c}\text { Implant }(N=66) \\
43\end{array}$} \\
\hline Sex & Male & \\
\hline & Female & 23 \\
\hline \multirow[t]{4}{*}{ Age } & $<50$ years & 6 \\
\hline & $50-59$ years & 35 \\
\hline & $60-69$ years & 11 \\
\hline & $>69$ years & 14 \\
\hline \multirow[t]{6}{*}{ Location } & Maxilla Premolar & 3 \\
\hline & Maxilla First molar & 21 \\
\hline & Maxilla Second molar & 10 \\
\hline & Mandible Premolar & 5 \\
\hline & Mandible First molar & 13 \\
\hline & Mandible Second molar & 14 \\
\hline \multirow[t]{3}{*}{ Implant Diameter } & $4 \mathrm{~mm}$ & 3 \\
\hline & $4.5 \mathrm{~mm}$ & 16 \\
\hline & $5 \mathrm{~mm}$ & 47 \\
\hline \multirow[t]{3}{*}{ Implant Length } & $7 \mathrm{~mm}$ & 15 \\
\hline & $8.5 \mathrm{~mm}$ & 48 \\
\hline & $10 \mathrm{~mm}$ & 3 \\
\hline \multirow[t]{3}{*}{ Collar Height } & $1.8 \mathrm{~mm}$ & 2 \\
\hline & $2 \mathrm{~mm}$ & 47 \\
\hline & $2.8 \mathrm{~mm}$ & 17 \\
\hline
\end{tabular}


Table 2. Various factors and MBL

\begin{tabular}{|c|c|c|c|c|}
\hline \multirow{2}{*}{ Factors } & \multirow{2}{*}{$\mathrm{N}$} & \multicolumn{3}{|c|}{$\operatorname{MBL}(\mathrm{mm})$} \\
\hline & & Mesial & Distal & Mean \\
\hline \multicolumn{5}{|l|}{ Sex } \\
\hline Male & 43 & $0.27 \pm 0.59$ & $0.38 \pm 0.45$ & $0.33 \pm 0.37$ \\
\hline Female & 23 & $0.38 \pm 0.58$ & $0.57 \pm 0.69$ & $0.47 \pm 0.5$ \\
\hline
\end{tabular}

Age

$\begin{array}{lllll}<60 \text { years } & 41 & 0.32 \pm 0.60 & 0.47 \pm 0.57 & 0.37 \pm 0.42 \\ \geq 60 \text { years } & 25 & 0.29 \pm 0.57 & 0.41 \pm 0.52 & 0.35 \pm 0.44\end{array}$

Hypertension

Yes 21

21

$0.26 \pm 0.50$

$0.36 \pm 0.47$

$0.30 \pm 0.37$

No

$0.33 \pm 0.62$

$0.50 \pm 0.57$

$0.41 \pm 0.44$

Diabetes

Yes

No

Location

Maxilla

Mandible

Diameter

$$
\begin{aligned}
& <5 \mathrm{~mm} \\
& \geq 5 \mathrm{~mm}
\end{aligned}
$$

Length

$$
\begin{array}{r}
7 \mathrm{~mm} \\
>7 \mathrm{~mm}
\end{array}
$$

Collar height

$$
\begin{aligned}
& \leq 2.0 \mathrm{~mm} \\
& 2.8 \mathrm{~mm}
\end{aligned}
$$$$
49
$$

Splinted prosthesis

$$
\text { Yes }
$$

No

Bone grafting

$$
\text { Yes }
$$$$
\text { No }
$$

16

50

34

32

19

47

15

51

51

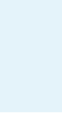

$$
\begin{aligned}
& 0.28 \pm 0.45 \\
& 0.32 \pm 0.63
\end{aligned}
$$

$$
0.35 \pm 0.53
$$$$
0.27 \pm 0.64
$$

$0.41 \pm 0.52$

$0.54 \pm 0.45$

$0.41 \pm 0.32$

$0.42 \pm 0.60$

$0.37 \pm 0.45$

.446

.268

.187

$\begin{array}{lll}0.52 \pm 0.60 & 0.48 \pm 0.62 & 0.50 \pm 0.48 \\ 0.24 \pm 0.57 & 0.43 \pm 0.53 & 0.34 \pm 0.40\end{array}$
$0.14 \pm 0.50$
$0.38 \pm 0.61$

$0.42 \pm 0.43$

$0.28 \pm 0.40$

$0.46 \pm 0.59$

$0.42 \pm 0.43$ 


\section{Effect of implant insertion depth on MBL and implant thread exposure}

The mean MBL values were $0.12,0.32$, and $0.65 \mathrm{~mm}$ in groups $\mathrm{A}, \mathrm{B}$, and $\mathrm{C}$, respectively. MBL was higher in group $\mathrm{C}$ than in groups $\mathrm{A}$ and $\mathrm{B}(p<.001)$ (Table 3 and Fig. 3). The thread exposure frequencies were $40.9 \%, 21.1 \%$, and $12.0 \%$ in groups $\mathrm{A}, \mathrm{B}$, and $\mathrm{C}$, respectively. As the implant insertion depth increased, the frequency of thread exposure tended to decrease, and this result was statistically significant $(p=.023)$ (Table 4 and Fig. 4).

\section{Table 3. Implant insertion depth and MBL}

\begin{tabular}{|c|c|c|c|c|c|c|}
\hline \multirow{2}{*}{$\begin{array}{l}\text { Implant insertion depth } \\
\text { (mm) }\end{array}$} & \multirow{2}{*}{ Implant N } & \multicolumn{3}{|c|}{$\mathrm{MBL}(\mathrm{mm})$} & \multirow{2}{*}{$\begin{array}{c}p \text {-value } \\
\text { (one-way ANOVA) }\end{array}$} & \multirow{2}{*}{$\begin{array}{l}\text { Dunnett } \\
\text { T3 }\end{array}$} \\
\hline & & Mesial & Distal & Mean & & \\
\hline$<0.5 \mathrm{~mm}^{\mathrm{A}}$ & 22 & $0.09 \pm 0.48$ & $0.16 \pm 0.39$ & $0.12 \pm 0.36$ & \multirow{3}{*}{$<.001$} & \multirow{3}{*}{$\mathrm{A}, \mathrm{B}<\mathrm{C}$} \\
\hline $0.5 \mathrm{~mm}-1.0 \mathrm{~mm}^{\mathrm{B}}$ & 19 & $0.28 \pm 0.54$ & $0.36 \pm 0.36$ & $0.32 \pm 0.26$ & & \\
\hline$>1.0 \mathrm{~mm}^{\mathrm{C}}$ & 25 & $0.53 \pm 0.64$ & $0.77 \pm 0.62$ & $0.65 \pm 0.43$ & & \\
\hline Total & 66 & $0.31 \pm 0.59$ & $0.48 \pm 0.55$ & $0.38 \pm 0.42$ & & \\
\hline
\end{tabular}

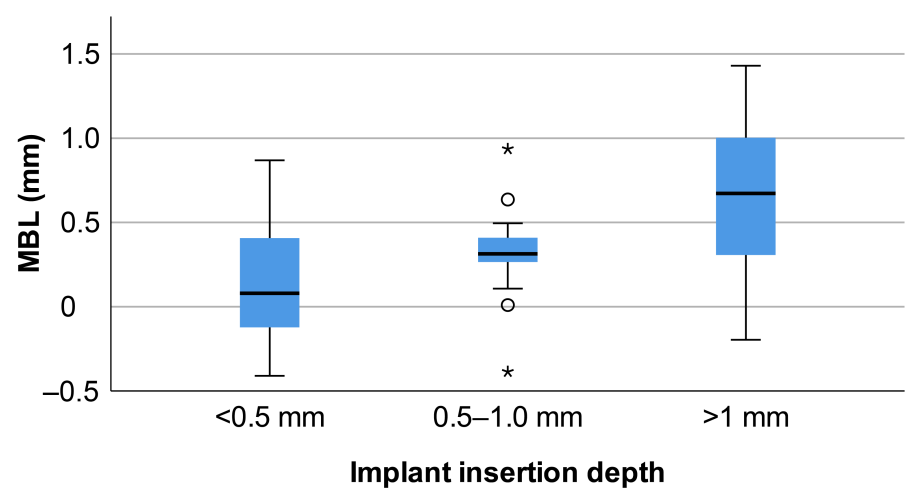

Fig. 3. Implant insertion depth and MBL.

Table 4. Implant insertion depth and frequency of thread exposure

\begin{tabular}{|c|c|c|c|c|}
\hline \multirow{2}{*}{ Implant insertion depth } & \multicolumn{2}{|c|}{ Thread exposure } & \multirow{2}{*}{ Sum } & \multirow{2}{*}{$\chi^{2}$} \\
\hline & No exposure & Exposure & & \\
\hline$<0.5 \mathrm{~mm}^{\mathrm{A}}$ & $13(59.1 \%)$ & $9(40.9 \%)$ & 22 & \multirow{3}{*}{$\begin{array}{c}5.179 \\
(p=.023)\end{array}$} \\
\hline $0.5 \mathrm{~mm}-1.0 \mathrm{~mm}^{\mathrm{B}}$ & $15(78.9 \%)$ & $4(21.1 \%)$ & 19 & \\
\hline$>1.0 \mathrm{~mm}^{\mathrm{C}}$ & $22(88.0 \%)$ & $3(12.0 \%)$ & 25 & \\
\hline
\end{tabular}




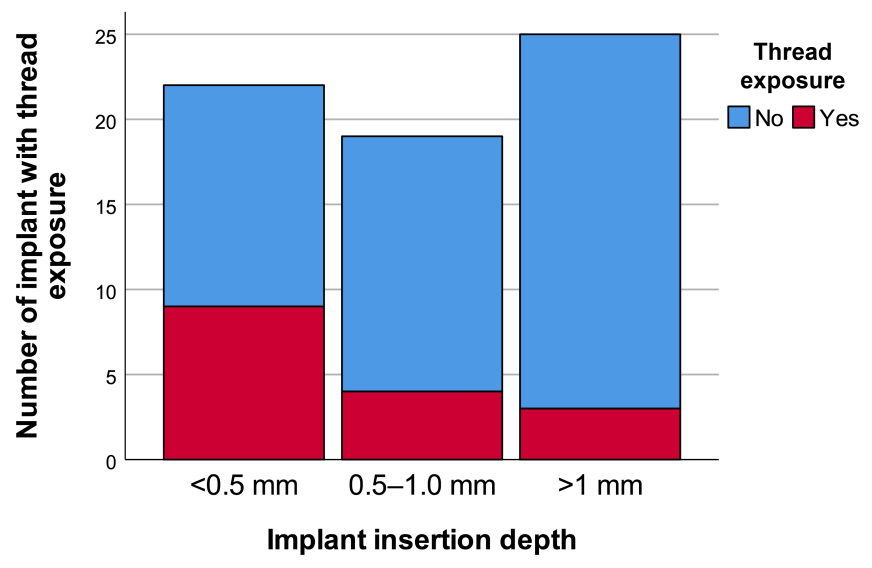

Fig. 4. Implant thread exposure frequency according to implant insertion depth.

\section{IV . Discussion}

MBL can be influenced by various factors. Guven et al. ${ }^{16}$ reported that age, history of periodontitis, oral hygiene, abrasions, smoking, implant location, implant surface, implant length, surgical procedure type, and prosthesis type were statistically significant for MBL. Schwarz et al. ${ }^{17}$ reported that factors such as history of periodontitis, smoking, diabetes, poor plaque control, keratinized mucosa, excess cement, systemic conditions, and occlusal overload are risk factors for peri-implantitis and MBL. In this study, patient-related factors such as sex, age, hypertension, and diabetes were not statistically significant for MBL. The reason is that this study investigated the initial MBL approximately one year after implant placement. Lombardi et al. ${ }^{18}$ reported that initial MBL is a bone remodeling process that is mainly caused by non-infective causes such as surgical trauma, micro-gap, and occlusal overload. Periimplantitis is an infectious disease caused by bacteria. Given that plaque deposition and inflammatory reaction precede MBL, its effect on MBL in the first year after implant placement is limited. ${ }^{17}$ Long-term clinical studies are needed to investigate the effect of systemic factors on MBL.

Canullo et al. ${ }^{19}$ reported that biomechanical factors such as implant length or diameter had no effect on MBL. Similarly, the length and diameter of the implant were not statistically significant with MBL in the current study. In finite element analysis, occlusal force is concentrated in the crestal area, and the length of the implant does not affect the distribution of occlusal force. ${ }^{20,21}$ Qian et al. ${ }^{5}$ reported that the diameter of the implant is more important than the length of the implant in terms of stress distribution, but many studies have shown that the effect of diameter on MBL is limited. ${ }^{22,23}$

MBL was $0.46 \pm 0.43 \mathrm{~mm}$ in the group with bone grafting and $0.31 \pm 0.42 \mathrm{~mm}$ in the group without bone grafting. The amount of MBL was greater in the bone grafting group, but the difference was not statistically significant. Bone grafting is a highly predictable treatment method for the long-term survival 
of implants, but it is controversial whether the amount of MBL is greater in augmented bone. ${ }^{24-26}$ Further research is needed to identify the effect of bone grafting on MBL.

Splinted implant prostheses disperse the occlusal force of the implant, reduce prosthetic complications, and show better prognosis in short implants. ${ }^{27-29}$ However, if the splinted restoration is improperly designed, it can make it difficult to maintain proper oral hygiene.$^{30}$ In terms of MBL, there are insufficient studies on whether splinted prostheses affect MBL. In the current study, there was no statistical difference between the splinted and non-splinted implant groups.

Implant insertion depth had a statistically significant relationship with MBL. The initial MBL increased as the implant insertion depth increased. In particular, the initial MBL was significantly greater in the group with implant insertion depth $>1.0 \mathrm{~mm}$ than in the group with implant insertion depth $<1.0 \mathrm{~mm}$ $(p<.001)$. This result was in accordance with those of Lombardi et al. ${ }^{18}$ and Kim et al. ${ }^{31}$ Hammerle et al. ${ }^{32}$ observed a $1.1 \mathrm{~mm}$ increase in MBL when smooth surface implants were placed $1 \mathrm{~mm}$ below the alveolar crest compared with those placed at the crestal level. Hermann et al. ${ }^{33}$ conducted an experiment to investigate the effect of the implant-abutment interface on MBL. The implant rough/smooth border was placed under the crest of the bone. As a result, MBL occurred. The rough/smooth surface interface was $2 \mathrm{~mm}$ below the bone crest, and $1.88 \mathrm{~mm}$ of junctional epithelium and $1.05 \mathrm{~mm}$ of connective tissue contact were formed.

However, as the implant insertion depth increased, the probability of implant thread exposure tended to decrease. Lombardi et al. ${ }^{18}$ reported that the initial MBL occurred only up to six months after the loading of implants placed in a subcrestal position, and the presence of coronal bone on the implant shoulder acts as a biological shield. In the experiment of Hermann et al., ${ }^{34}$ the boundary of the marginal bone formed at the rough/smooth border and then stabilized in tissue-level implants. Vervaeke et al. ${ }^{35}$ reported that thin biotype patients had a significantly better bone level and less implant thread exposure in subcrestal implants than in equicrestal implants because it was advantageous in the reestablishment of biologic width. Fickl et al. ${ }^{36}$ reported a vertical bone loss of $0.7 \mathrm{~mm}$ when the full-thickness flap was opened. Maier et $\mathrm{al}^{37}$ reported that when the flapless implant placement group and implant placement with raising a mucoperiosteal flap group were compared, vertical bone resorption occurred by $0.55 \mathrm{~mm}$ more in the latter group.

MBL and thread exposure also occur frequently on the buccolingual side of implants. ${ }^{38}$ However, the location of the implant abutment interface, the thickness of the buccal bone, and the gingival biotype of the implant have important effects on MBL and thread exposure on the buccal side of the implant. ${ }^{39}$ It is difficult to study the thickness of the buccal bone and the MBL on the buccal-lingual side by using 2D radiographs. Therefore, this topic should be investigated by clinical studies and computed tomography rather than $2 \mathrm{D}$ radiographs. 
This study investigated the factors affecting the MBL of tissue-level implants. It was confirmed that MBL increased as the implant insertion depth increased, whereas thread exposure decreased. The other factors investigated in this study did not have a statistically significant effect on MBL. However, this study had several limitations. Owing to the low resolution and overlapping of panoramic radiographs, it is difficult to measure MBL accurately. Given the insufficient sample size and nature of the retrospective study, the results are less reliable. Further research is necessary to reduce the MBL of tissue-level implants and to establish an appropriate implant insertion depth.

\section{Conclusion}

Sex, age, hypertension, diabetes, implant length, implant diameter, implant location, collar height, bone grafting, and splinted implant prosthesis did not have a statistically significant effect on MBL. MBL increased as the implant insertion depth increased. In particular, a larger MBL occurred in the group with implant insertion depth $>1 \mathrm{~mm}$ than in the group with implant insertion depth $<1 \mathrm{~mm}$. By contrast, the frequency of implant thread exposure decreased as the implant insertion depth increased. Considering that there are limitations in this study, such as insufficient sample size, short follow-up period, low-resolution 2D radiographs, and retrospective type, in which variable control is difficult, further studies are needed to investigate other factors that affect MBL and proper implant insertion depth.

\section{Conflict of Interest}

The authors declare no conflict of interest. This research was supported by a grant of the Korea Health Technology R\&D Project through the Korea Health Industry Development Institute (KHIDI), funded by the Ministry of Health \& Welfare, Republic of Korea (grant number: HI20C0129020121).

\section{References}

1. Moraschini V, Poubel LA, Ferreira VF, Barboza Edos S. Evaluation of survival and success rates of dental implants reported in longitudinal studies with a follow-up period of at least 10 years: a systematic review. Int J Oral Maxillofac Surg 2015;44:377-88.

2. Schwartz-Arad D, Herzberg R, Levin L. Evaluation of long-term implant success. J Periodontol 2005;76:1623-8.

3. Vaillancourt H, Pilliar R, McCammond D. Finite element analysis of crestal bone loss around porous-coated dental implants. J Appl Biomater 1995;6:267-82.

4. Snauwaert K, Duyck J, van Steenberghe D, Quirynen M, Naert I. Time dependent failure rate and marginal bone loss of implant supported prostheses: a 15-year follow-up study. Clin Oral Investig 
2000;4:13-20.

5. Qian J, Wennerberg A, Albrektsson T. Reasons for marginal bone loss around oral implants. Clin Implant Dent Relat Res 2012;14:792-807.

6. Kim S, Jung UW, Cho KS, Lee JS. Retrospective radiographic observational study of 1692 Straumann tissue-level dental implants over 10 years: I. Implant survival and loss pattern. Clin Implant Dent Relat Res 2018;20:860-6.

7. Callan DP, O'Mahony A, Cobb CM. Loss of crestal bone around dental implants: a retrospective study. Implant Dent 1998;7:258-66.

8. Broggini N, McManus LM, Hermann JS, Medina R, Schenk RK, Buser D, et al. Peri-implant inflammation defined by the implant-abutment interface. J Dent Res 2006;85:473-8.

9. Hermann JS, Schoolfield JD, Schenk RK, Buser D, Cochran DL. Influence of the size of the microgap on crestal bone changes around titanium implants. A histometric evaluation of unloaded non-submerged implants in the canine mandible. J Periodontol 2001;72:1372-83.

10. Broggini N, McManus LM, Hermann JS, Medina RU, Oates TW, Schenk RK, et al. Persistent acute inflammation at the implant-abutment interface. J Dent Res 2003; 82:232-7.

11. Iglhaut G, Becker K, Golubovic V, Schliephake H, Mihatovic I. The impact of dis-/reconnection of laser microgrooved and machined implant abutments on soft- and hard-tissue healing. Clin Oral Implants Res 2013;24:391-7.

12. Becker K, Mihatovic I, Golubovic V, Schwarz F. Impact of abutment material and dis-/re-connection on soft and hard tissue changes at implants with platform-switching. J Clin Periodontol 2012;39:77480.

13. Derks J, Schaller D, Hakansson J, Wennstrom JL, Tomasi C, Berglundh T. Effectiveness of implant therapy analyzed in a swedish population: prevalence of peri-implantitis. J Dent Res 2016;95:43-9.

14. Wennerberg A, Albrektsson T. Effects of titanium surface topography on bone integration: a systematic review. Clin Oral Implants Res 2009;20:172-84.

15. Kumar VV, Sagheb K, Kämmerer PW, Al-Nawas B, Wagner W. Retrospective clinical study of marginal bone level changes with two different screw-implant types: comparison between tissue level (TE) and bone level (BL) implant. J Maxillofac Oral Surg 2014;13:259-66.

16. Güven SŞ, Cabbar F, Güler N. Local and systemic factors associated with marginal bone loss around dental implants: a retrospective clinical study. Quintessence Int 2020;51:128-41.

17. Schwarz F, Derks J, Monje A, Wang HL. Peri-implantitis. J Clin Periodontol 2018;45:S246-66.

18. Lombardi T, Berton F, Salgarello S, Barbalonga E, Rapani A, Piovesana F, et al. Factors influencing early marginal bone loss around dental implants positioned subcrestally: a multicenter prospective clinical study. J Clin Med 2019;8:1168.

19. Canullo L, Iannello G, Penarocha M, Garcia B. Impact of implant diameter on bone level changes around platform switched implants: preliminary results of 18 months follow-up a prospective randomized match-paired controlled trial. Clin Oral Implants Res 2012;23:1142-6.

20. Himmlova L, Dostalova T, Kacovsky A, Konvickova S. Influence of implant length and diameter on stress distribution: a finite element analysis. J Prosthet Dent 2004;91:20-5.

21. Sevimay M, Turhan F, Kilicarslan MA, Eskitascioglu G. Three-dimensional finite element analysis of the effect of different bone quality on stress distribution in an implant-supported crown. J Prosthet Dent 2005;93:227-34.

22. Atieh MA, Ibrahim HM, Atieh AH. Platform switching for marginal bone preservation around 
dental implants: a systematic review and meta-analysis. J Periodontol 2010;81:1350-66.

23. Mumcu E, Bilhan H, Cekici A. Marginal bone loss around implants supporting fixed restorations. J Oral Implantol 2011;37:549-58.

24. Jung RE, Herzog M, Wolleb K, Ramel CF, Thoma DS, Hammerle CH. A randomized controlled clinical trial comparing small buccal dehiscence defects around dental implants treated with guided bone regeneration or left for spontaneous healing. Clin Oral Implants Res 2017;28:348-54.

25. Blanco J, Alonso A, Sanz M. Long-term results and survival rate of implants treated with guided bone regeneration: a 5-year case series prospective study. Clin Oral Implants Res 2005;16:294-301.

26. Zitzmann NU, Scharer P, Marinello CP. Long-term results of implants treated with guided bone regeneration: a 5-year prospective study. Int J Oral Maxillofac Implants 2001;16:355-66.

27. Nissan J, Gross O, Ghelfan O, Priel I, Gross M, Chaushu G. The effect of splinting implant-supported restorations on stress distribution of different crown-implant ratios and crown height spaces. J Oral Maxillofac Surg 2011;69:2990-4.

28. Yilmaz B, Seidt JD, McGlumphy EA, Clelland NL. Comparison of strains for splinted and nonsplinted screw-retained prostheses on short implants. Int JOral Maxillofac Implants 2011;26:117682.

29. Mendonça JA, Francischone CE, Senna PM, Matos de Oliveira AE, Sotto-Maior BS. A retrospective evaluation of the survival rates of splinted and non-splinted short dental implants in posterior partially edentulous jaws. J Periodontol 2014;85:787-94.

30. Ravidà A, Saleh MH, Muriel MC, Maska B, Wang HL. Biological and technical complications of splinted or nonsplinted dental implants: a decision tree for selection. Implant Dent 2018;27:89-94.

31. Kim YT, Lim GH, Lee JH, Jeong SN. Marginal bone level changes in association with different vertical implant positions: a 3-year retrospective study. J Periodontal Implant Sci 2017;47:231-9.

32. Hämmerle CH, Brägger U, Bürgin W, Lang NP. The effect of subcrestal placement of the polished surface of ITI ${ }^{\circledR}$ implants on marginal soft and hard tissues. Clin Oral Implants Res 1996;7:111-9.

33. Hermann JS, Buser D, Schenk RK, Higginbottom FL, Cochran DL. Biologic width around titanium implants. A physiologically formed and stable dimension over time. Clin Oral Implants Res 2000;11:1-11.

34. Hermann JS, Buser D, Schenk RK, Cochran DL. Crestal bone changes around titanium implants. A histometric evaluation of unloaded non-submerged and submerged implants in the canine mandible. J Periodontol 2000;71:1412-24.

35. Vervaeke S, Matthys C, Nassar R, Christiaens V, Cosyn J, De Bruyn H. Adapting the vertical position of implants with a conical connection in relation to soft tissue thickness prevents early implant surface exposure: A 2-year prospective intra-subject comparison. J Clin Periodontol 2018;45:60512.

36. Fickl S, Kebschull M, Schupbach P, Zuhr O, Schlagenhauf U, Hurzeler MB. Bone loss after fullthickness and partial-thickness flap elevation. J Clin Periodontol 2011;38:157-62.

37. Maier FM. Initial crestal bone loss after implant placement with flapped or flapless surgery-a prospective cohort study. Int J Oral Maxillofac Implants 2016;31:876-83.

38. González-Martín O, Oteo C, Ortega R, Alandez J, Sanz M, Veltri M. Evaluation of peri-implant buccal bone by computed tomography: an experimental study. Clin Oral Implants Res 2016;27:950-5.

39. Merheb J, Quirynen M, Teughels W. Critical buccal bone dimensions along implants. Periodontology 2000 2014;66:97-105. 